\title{
Hangi kalça kırığında endoprotez; parsiyel mi, total mi?
}

\author{
In which hip fracture endoprosthesis is required; partial or total?
}

\author{
Fatih Yıldız, Muzaffer Ağır
}

Bezmialem Vakıf Üniversitesi, Ortopedi ve Travmatoloji Ana Bilim Dalı, İstanbul

\begin{abstract}
Kalça kırı̆̆ı tıbbi, ekonomik ve sosyal yönleri ile önemli bir toplum sağlığı sorunudur. Yüksek mortalite, morbidite, komplikasyonlar ve maliyetler nedeniyle temel amaç kalça kırıklarının önlenmesi olmalıdır. Ayrışmış kalça kırıklarının tamamı ve ayrışmamış kırıkların büyük bölümü cerrahi olarak tedavi edilir ve osteosentez amacıyla kırık tespiti ya da artroplasti uygulanır. Bu seçeneklerden hangisinin daha doğru olduğuna dair fikir birliği yoktur ancak anatomik, fizyolojik ve komorbid pek çok faktöre göre karar verilmelidir. Fizyolojik olarak yaşlı, düşük aktiviteli ve osteoporotik hastaların femur baş ve boyun kırıklarının artroplasti ile tedavisi önerilmektedir. Bu grup içerisinde de görece uzun yaşam beklentili hastaların total kalça artroplastisi ile tedavisi güncel genel kabul görmüş yaklaşımdır.
\end{abstract}

Anahtar sözcükler: kalça kırığı; hemiartroplasti; total kalça artroplastisi; parsiyel kalça artroplastisi
The hip fracture is a public health problem with medical, economic and social aspects. Primary aim should be prevention of the hip fracture instead of treatment because of its high mortality, morbidity, complication rates and financial burden. All displaced and most of the nondisplaced hip fractures are treated surgically with fixation for osteosynthesis or hip arthroplasty. There is not a consensus in the literature regarding the best method however; decision should be made according to many anatomical, physiological, and comorbid factors. Hip replacement is the recommendation for femoral head or neck fractures of the physiologically elderly, patients with low level activity and severe osteoporosis. Among this group, total hip arthroplasty is a widely accepted current option for patients with longer life expectancies.

Key words: hip fracture; hemiarthroplasty; total hip arthroplasy; partial hip arthroplasty; hip replacement
K alça kırıkları, diğer kas-iskelet sistemi yaralanmalarından farklı olarak, sağlık, sosyal ve ekonomik yönleri ile önemli bir halk sağlığı sorunudur. ${ }^{[1,2]}$ Kalça kırıklarının önlenmesi, çok alanlı (multidisipliner) yaklaşım ile doğru ve etkili tedavisi bu problemin olumsuz sonuçlarını olabildiğince azaltacaktır. Kalça kırıkları büyük oranda yaşlı popülasyonda karşımıza çıkmaktadır ancak yüksek enerjili travmalara ve patolojik durumlara bağlı olarak genç ve orta yaş grubundaki insanlarda da görülebilir. ${ }^{[1,3,4]}$ İnsan ömrünün uzaması, ileri yaşlı insanların kendi ihtiyaçlarını karşılama isteği ve daha hareketli yaşam tarzı, başta osteoporoz olmak üzere eşlik eden çeşitli hastalıklar ve sorunlar nedeni ile kalça kırıklı hastaların sayısı hızla artmaktadır. ${ }^{[5-7]}$ Gençlerden farklı olarak bu hastalarda uygulanan tedaviden elde edilecek sonuç, kalça kırığına yapılan doğru ve başarılı müdahaleler ile her zaman doğru orantılı olmayabilir. ${ }^{[1,3,4]}$ Kötü sonuçlar, ileri yaş hastalardaki ameliyat sürecindeki komplikasyonların en önemli sebebi olan ciddi sistemik patolojiler, ameliyat öncesi olumsuz fonksiyonel, bilişsel ve sosyal durumlar ile doğrudan ilişkilidir. ${ }^{[1,6]}$ Geriatrik kalça kırıklarında bir yıllık mortalitenin \%14-36 gibi oldukça yüksek oranda olduğu bilinmektedir. ${ }^{[5,8,9]}$ Demans, bakım evinde yaşıyor olmak, kırık öncesi kısıtlı hareketlilik, konjestif kalp yetmezliği, erkek cinsiyet, ameliyat sonrası derin yara enfeksiyonu, pnömoni ve yatışta ortaya çıkan deliryum mortalite ile doğrudan ilişkili faktörler arasındadır. ${ }^{[1,6,10]}$ Özellikle kalça kırıklı ileri yaşlı hastalarda olmak üzere, ameliyat sonrası kötü fonksiyonel sonuç, komplikasyon, morbidite ve mortaliteyi en aza indirebilmek için ameliyat öncesi dönemde hastaların sosyal, fonksiyonel ve medikal açıdan ayrıntılı olarak değerlendirilmesi önemlidir. ${ }^{[1,7,11]}$ Kalça kırıklı bir hastanın tedavisindeki temel amaç; hastayı kırık öncesi fonksiyonel seviyesine getirirken tekrar ameliyatlar gerektirebilecek ve ölümcül seyredebilecek ana komplikasyonlardan kaçınmaktır. ${ }^{[6]}$

- Illetişim adresi: Doç. Dr. Fatih Yıldız, Bezmialem Vakıf Üniversitesi, Ortopedi ve Travmatoloji Ana Bilim Dalı, Adnan Menderes Bulvarı, 34093 Fatih, İstanbul Tel: 0505 - 9343033 E-posta: yildizfatih@hotmail.com

- Geliştarihi: 5 Ocak $2021 \quad$ Kabul tarihi: 27 Ocak 2021

ORCID iD: Fatih Yıldız, 0000-0002-8552-0384 • Muzaffer Ağır, 0000-0003-1766-8413 


\section{EKLEM içi KALÇA KIRIKLARI}

\section{Femur Başı Kırıklarında Endoprotez}

Kalça kırığı tipleri arasında nadir görülen yaralanmalardır. Genellikle trafik kazaları gibi yüksek enerjili travmalara bağlı olarak, görece genç ve orta yaş grubunda görülür. Femur başı kırıkları sıklıkla kalça çıkığı ve asetabulum kırıkları ile birlikte görülür. ${ }^{[12]}$ Travma esnasındaki bacağın pozisyonu ve kuvvetin yönü, çıkığın yönünü, asetabulum ve femur başı kırıklarının tiplerini belirler. En sık posterior çıkıklar görülür ve femur başı, boynu, şaftı (cismi) veya kombinasyonu şeklindeki kırıklara eşlik edebilir. Anterior-posterior (ön-arka) pelvis grafisi, asetabular kırık eşlik ediyorsa Judet grafileri ve özellikle çıkığın eşlik ettiği hastalarda redüksiyon sonrası ince kesitli bilgisayarlı tomografi (BT) görüntülemeleri ile kırığın tipi, eşlik eden yaralanmalar, redüksiyon ve varsa eklem içi serbest kemik fragmanları değerlendirilebilir. Femur başı kırıklarını değerlendirmede en sık Pipkin sınıflaması kullanılmaktadır. ${ }^{[13]}$ Bu sınıflama femur başı kırığının yeri ve eşlik eden femoral veya asetabular kırık ve çıkığa göre yapılmıştır.

Femur başı kırıkları genellikle genç ve orta yaşlı, fiziksel olarak aktif popülasyonda görüldüğünden tedavide amaç anatomik redüksiyon ( $<1 \mathrm{~mm}$ ayrışma) ile birlikte dengeli ve uyumlu bir kalça elde etmek olmalıdır. ${ }^{[8]}$ Her ne kadar Pipkin tip 1 veya 2 kırıkları olan hastaları kapalı redüksiyon ve gerekirse fragman eksizyonu, açık redüksiyon ve internal tespit (ARIT) ile tedavi etmek mümkün olsa da Pipkin tip 3'de femur boyun kırığı da eşlik ettiğinden avasküler nekroz (AVN) riski nedeniyle kötü prognoza daha yatkındırlar. ${ }^{[14]}$ Dört yüz elli üç femur başı kırığını içeren bir sistematik derlemede, 26 Pipkin tip 3 hastasının tedavisi sonucunda genç hastalarda ARIT ve yaşlı hastalarda artroplasti uygulanması önerilmiştir. ${ }^{[15]}$ Özetle, fizyolojik olarak genç, aktif ve hafif ayrışmış ya da ayrışmamış kırığı olan hastalarda osteosentez uygulanmalı, bunun dışında kalan Pipkin tip 2 ve tip 3 kırıklı, ileri yaş ( $>50-60$ yaş), hareketsiz yaşam tarzı ve ayrışmış femur boyun kırığının eşlik ettiği hastalarda parsiyel veya total kalça artroplastisi (TKA) ilk seçenek olarak düşünülmelidir. ${ }^{[12,16]}$ Konservatif tedavinin veya ARiT'in başarısız olduğu, kaynamama, AVN veya travma sonrası osteoartrit gelişimine bağlı kalça ağrısı olan hastalarda da artroplasti endikasyonu bulunmaktadır (Şekil 1).

\section{Femur Boyun Kırıklarında Endoprotez}

Femur boyun kırıkları genellikle yaşlı, osteoporotik popülasyonda, düşük enerjili travmalar ile meydana gelmektedir ve kalça kırıklarının önemli bir kısmını oluşturmaktadır. ${ }^{[1,12,17]}$ Bununla birlikte, görece nadir de olsa (\%2-5) genç ve orta yaş grubunda yüksek enerjili travmalara bağlı olarak, eşlik eden asetabulum, femur diyafiz (cisim) kırığı veya kalça çıkığı ile birlikte de görülebilir. ${ }^{[12]}$
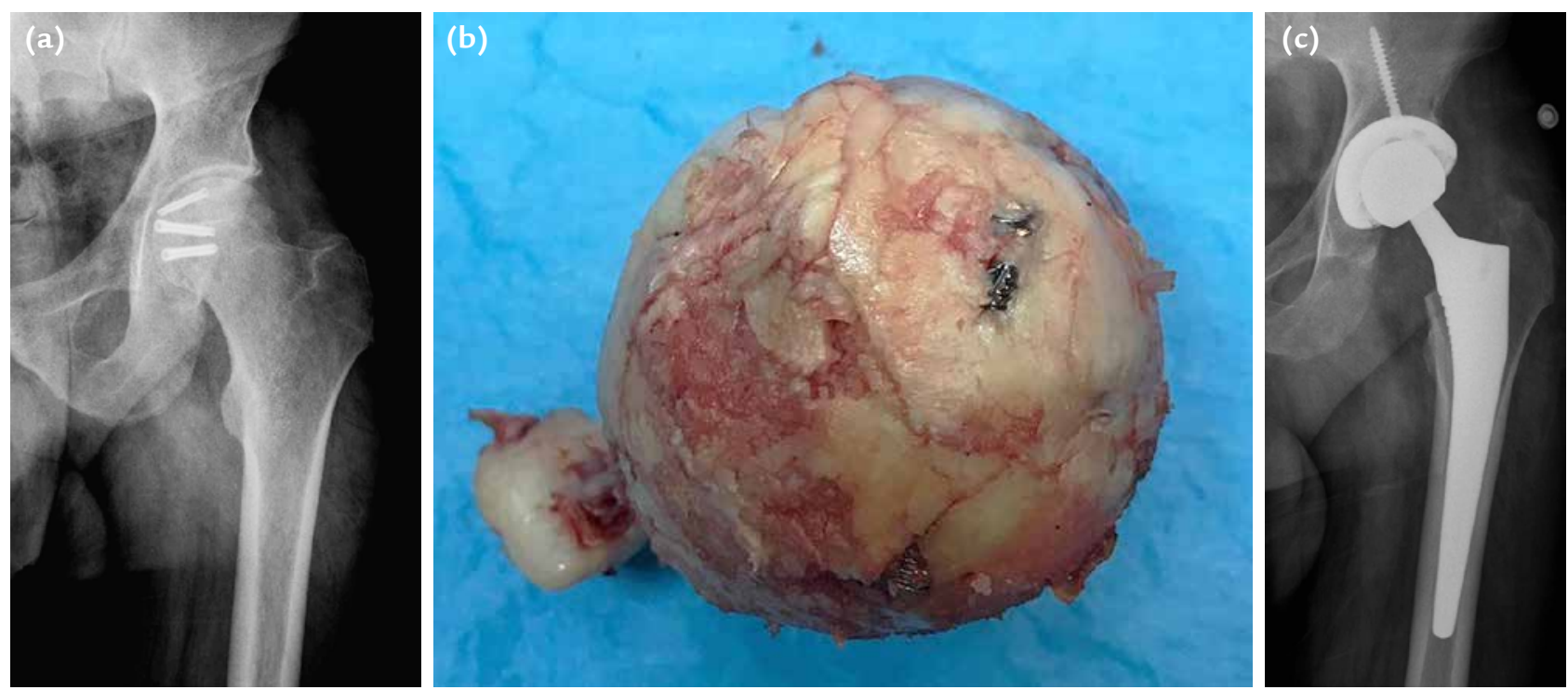

Şekil 1. a-c. Femur başı kırığı nedeni ile açık redüksiyon ve internal tespit yapılan 41 yaşındaki erkek hastada ameliyat sonrası 4. ayda gelişen femur başı avasküler nekrozu (a). Eksize edilen femur başında kıkırdak delaminasyonu, çökme ve vidaların başı deldiği görülmekte (b). Total kalça artroplastisi sonrası grafi (c). 

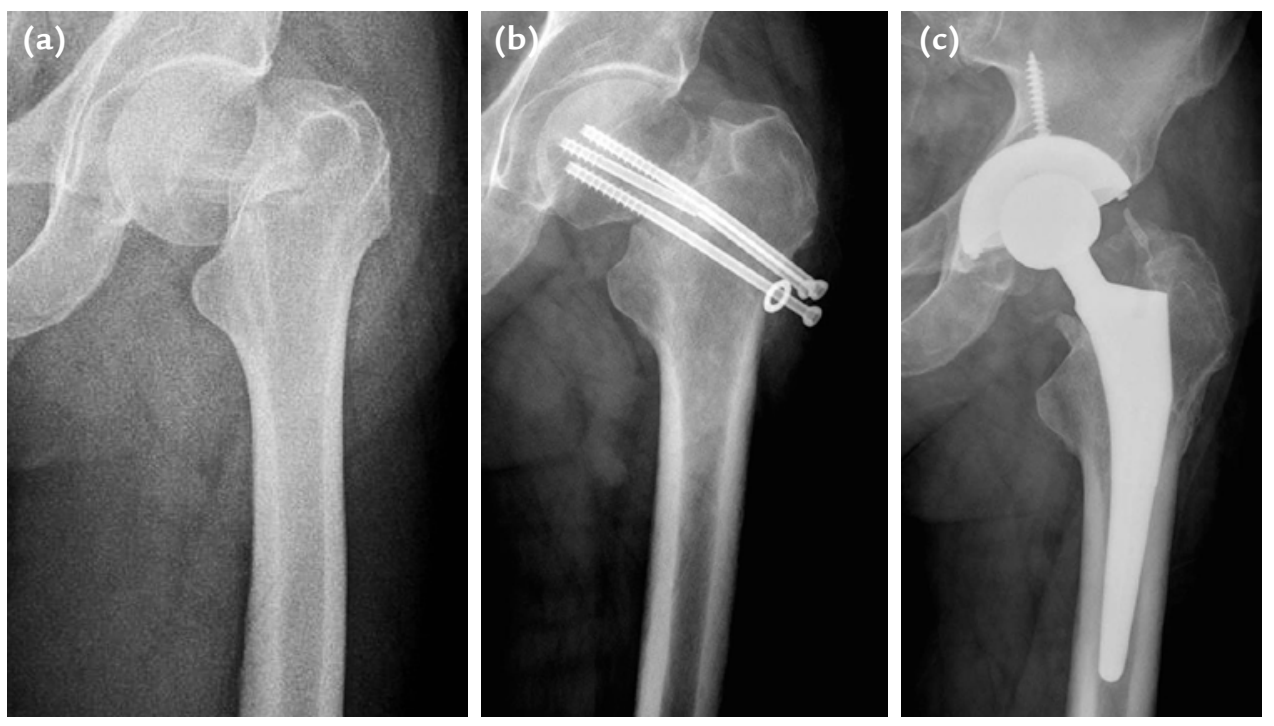

Şekil 2. a-c. Femur boyun kırığı olan 68 yaşında erkek hastanın kalça grafisi (a). Kapalı redüksiyon ve kanüllü vida ile tespit sonrası redüksiyon kaybı ve tespit yetersizliği görülmekte (b). Başarısız tespitin total kalça artroplastisi ile tedavisi (c).

Intertrokanterik kırıkların aksine, femur boyun kırıklarının kapsül içi olmaları, bu bölgenin anatomisi ve damarsal beslenme şekli, femur başının avasküler nekrozu ya da kaynamama riskini de beraberinde getirmektedir. ${ }^{[2,12]}$ Komorbiditeleri nedeniyle yüksek riskli ve düşük hareket kapasiteli bu hasta grubunda ameliyat sürecindeki komplikasyonlar yüksek mortaliteye sebep olmaktadır. Tedavi seçeneğine karar verirken, genç ve orta yaş hastaları (<65 yaş) artroplastinin kısa ve uzun dönemdeki muhtemel komplikasyonlarından, yaşlı (>75 yaş) ve komorbid hastaları ise başarısız osteosentez sonrası ikincil ameliyat gereksinimlerinden korumak hedeflenmelidir. ${ }^{[12]}$ Bu nedenle temel prensip olarak fizyolojik olarak genç ve aktif hastalarda osteosentez, ileri yaşlı ve düşük aktiviteli hastalarda ise artroplasti genel kabul görmüş tedavi yöntemleridir. Orta yaş grubu hastaların tedavisinde ise literatürde fikir birliği yoktur. Son yıllardaki genel eğilim, 65 yaş üzeri, aktif ve fonksiyonel beklentisi yüksek hastalarda da TKA uygulamak yönündedir. ${ }^{[5,6,12,17]}$ Osteosentez, parsiyel veya TKA'da çimentolu ve çimentosuz tespit alternatifleri bulunmaktadır. Hastanın fizyolojik yaşı, aktivite seviyesi, kemik kalitesi, kırık şekli, eşlik eden yaralanmalar ve ek hastalıklar tedavi seçeneğini belirlemede çok önemlidir. ${ }^{6,12,17-19]}$ Tedavinin hedefi ağrısız ve hareketli bir kalça elde ederken, hastanın olabilecek en kısa sürede, en az fonksiyonel kayıp ile hareketliliğinin sağlanmasıdır. Hastanın erken dönemde hareketlendirilmesi, muhtemel medikal komplikasyon risklerini de azaltmaktadır. ${ }^{[12]}$

Orta ve ileri yaş hasta grubunda femur boyun kırı̆ı nedeni ile yapılan osteosentez girişimleri başarısız olduğunda, çoğu zaman tekrarlayan cerrahi girişimler gerektiren kaynamama ve AVN gibi komplikasyonlar ile karşılaşılır. ${ }^{[6,10,12]}$ Bu nedenle her hastayı kendi özellikleri ile değerlendirerek uygun, seçilmiş orta yaş hastalar ve geriatrik kalça kırıklarına baştan artroplasti uygulamak, ikincil cerrahileri ve muhtemel komplikasyonları önlemek açısından daha doğrudur. ${ }^{12,17-19]}$ Kırığın kaynamaması başarısız sonuçların önemli nedenlerinden biridir ve ayrışmış femur boyun kırıklarının internal tespit ile tedavisi sonucunda çeşitli serilerde kaynamama oranları \%33'e varmaktadır. ${ }^{[20]}$ ïleri yaş, düşük kemik yoğunluğu, kırığın ayrışma miktarı ve kemik defektleri kaynamama riskini artırmaktadır. ${ }^{[20]}$ Diğer faktörlerin yanında, bu hastalarda anatomik kırık redüksiyonu ve kararlı bir tespit elde edilememesi kaynamama riskini oldukça artırmaktadır. ${ }^{[12]}$ Kaynamama ise uzuv ağrısı, aksama ve kötü fonksiyonel sonuçlara neden olmaktadır. Femur başı AVN, başarısız internal tespitin bir diğer sebebidir ve ayrışmış femur boyun kırıklarında \%30-35 oranında görülebilmektedir. ${ }^{[12,20]}$ Kemik kalitesinin iyi olduğu, diğer bir deyişle femur boyun kırığı için daha yüksek enerjili travma gerektiren genç ve orta yaş hastaların ayrışmış femur boyun kırıklarında bu oran daha da artmaktadır. Travma sonrası gelişen AVN sonucunda femur başı çökerek zaman içerisinde osteonekroza ikincil osteoartrite, sonuç olarak kalçada ağrı, hareket kısıtııı̆̆ı ve memnuniyetsizliğe neden olur. Femur boyun kırıklarının internal tespit ile tedavisinde iki önemli ortopedik komplikasyon olan kaynamama ve AVN için genç ve aktif hastalarda kalça koruyucu yöntemler ile tedavi hedeflenirken orta ve ileri yaş grubunda çoğu zaman nihai tedavi olarak artroplasti ile rekonstrüksiyon gerekmektedir (Şekil 2). Bu hastaların büyük kısmının ileri yaşa ve mortaliteyi artıran çeşitli komorbid faktörlere sahip 
oldukları da düşünüldügünnde, tedavi yaklaşımına karar verirken hastaları yalnızca yaş ve radyolojik olarak değil, fizyolojik, anatomik, tıbbi ve sosyal olarak bütüncül bir yaklaşım ile değerlendirmek gerekir. Bu nedenle femur boyun kırıklarının tedavisinde tespit kaybı, kaynamama veya AVN için yüksek riskli, seçilmiş, uygun orta yaş hastalarda ve tüm fizyolojik olarak ileri yaş, düşük aktiviteli hastalarda birincil artroplasti uygulanabilir. ${ }^{[17-19]}$

Moore tarafından femur başı replasmanının geliştirilmesi ve 1952 yılında ilk sonuçların yayımlanması, hemen arkasından yakın zamana kadar ülkemizde de yaygın bir şekilde kullanılan Thompson protezinin geliştirilmesi ile femur boyun kırıklarının tedavisinde artroplasti seçeneği kabul görmüş ve iyi sonuçlar alınmıştır. ${ }^{[6,12]}$ illeri yaş hastalarda, ayrışmamış (Garden tip 1 ve tip 2) femur kırıklarının tedavisinde, internal tespitin hemiartroplastiye göre ameliyat ve hastanede yatış süreleri, ameliyat sürecindeki komplikasyonlar, ağrı, hareket kabiliyeti ve bir yıllık mortalite açısından daha üstün olduğunu gösteren çalışmalara karşın tespit kaybı ve tekrar ameliyat gereksinimleri nedeniyle baştan artroplasti uygulanmasını öneren çalışmalar da bulunmaktadır. ${ }^{[12]}$ Ayrışmış femur boyun kırıklarında (Garden tip 3 ve tip 4) da genç ve orta yaşlı hastalarda ilk tedavi seçeneği kapalı ya da açık redüksiyon ve internal tespit olmalıdır. Ancak kronolojik yaş tek başına fizyolojik durum, kemik kalitesi, aktivite düzeyi ve yaşam beklentisini göstermediğinden tüm bu faktörler ayrı ayrı göz önünde bulundurularak, osteosentezin başarısız olma ihtimalinin yüksek olduğu fizyolojik olarak ileri yaştaki, kemik mineral yoğunluğunun düşük, kırığın parçalı ve yeterli tespit elde etmenin zor olabildiği subkapital yerleşimli kırıklı hastalarda artroplasti birincil ameliyat olarak düşünülmelidir. ${ }^{[6,17-19]}$ Enflamatuvar artropatiler, kronik böbrek veya karaciğer yetmezliği gibi ağır ek hastalıkların eşlik ettiği veya kırık öncesi koksartrozu bulunan hastalarda da artroplasti önerilmektedir. ${ }^{[6,12]}$

\section{Parsiyel mi, Total Kalça Protezi mi?}

Fizyolojik olarak ileri yaş hastalarda yaşam beklentisinin de az olması nedeniyle hemiartroplasti uygulayarak osteosentezin implant yetmezliği, tespit kaybı, kaynamama ve avasküler nekroz gibi komplikasyonlarından korunmak mümkündür. Bu grup içerisindeki görece genç ve aktif hastalarda ise baştan TKA uygulayarak ileride gelişebilecek asetabular kıkırdak erozyonuna bağlı ağrı ve hemiartroplastinin total proteze revize edilme riski de ortadan kaldırılmış olur (Şekil 3). ${ }^{[5,6,12,17-19]}$

Parsiyel veya total kalça protezi kararı verirken literatürde kesin bir yaş sınırı yoktur. ${ }^{\left[{ }^{[]}\right.}$Kimi yazarlar 80 yaşına kadar olan hastalarda TKA uygulanmasını önerirken, bazı yazarlar da 5 yıl ve daha fazla yaşam beklentisi olan, kendi başına ve ev dışı hareket kabiliyeti olan hastalarda, ileride gelişebilecek asetabular kıkırdak erozyonu veya protrüzyona bağlı muhtemel revizyon ihtiyaçları nedeniyle baştan TKA uygulanmasını önermektedirler. ${ }^{[21]}$ Yaşam beklentisi ile ilgili kanıya varmak için yukarıda da belirtildiği üzere hastaları tıbbi, fonksiyonel ve sosyal açıdan iyi değerlendirmek gerekir. ${ }^{[17-19]}$ Kalça kırıkları genellikle yaşılarda görülür
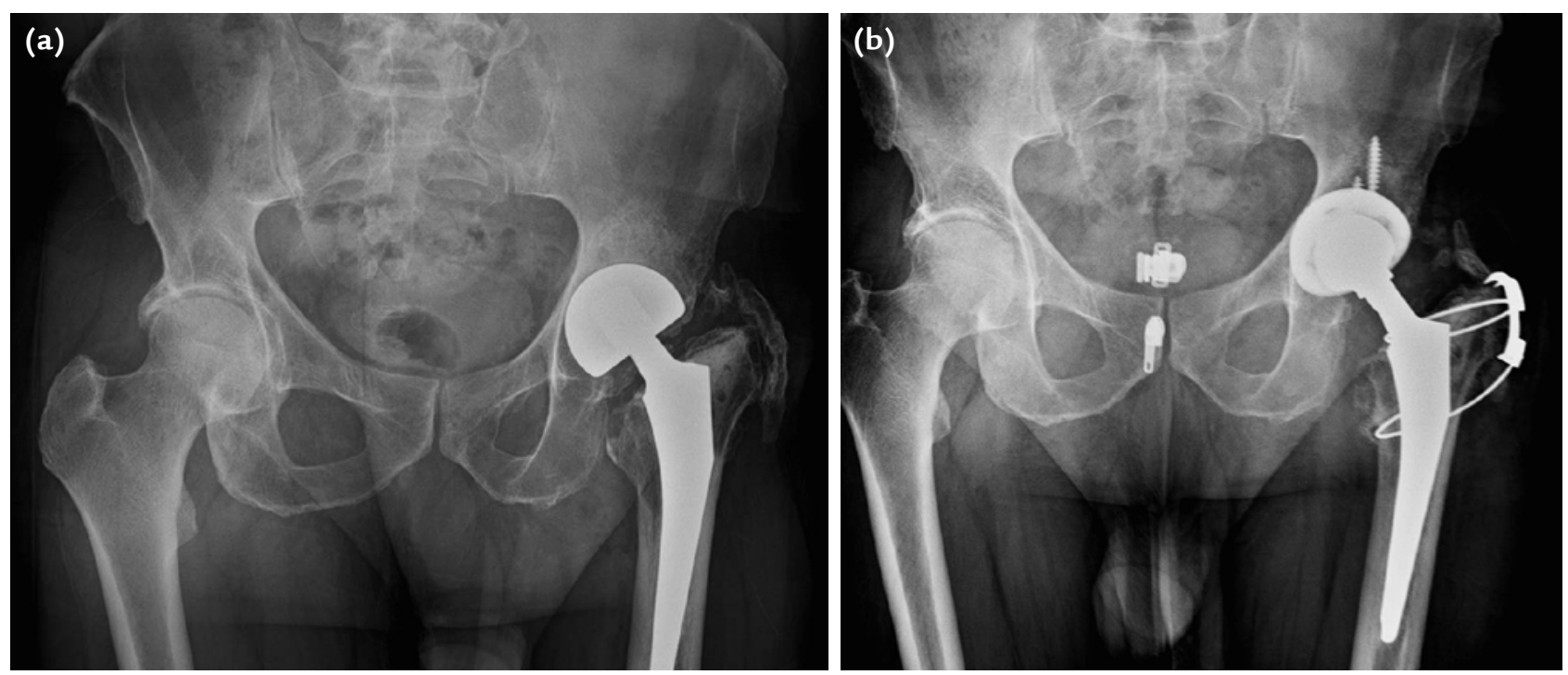

Şekil 3. a, b. Femur boyun kırığı nedeni ile dokuz yıl önce parsiyel kalça artroplastisi yapılan 69 yaşındaki hastada zaman içerisinde gelişen asetabular erozyon görülmekte (a). Aynı hastanın total kalça artroplastisi ile tedavisi (b). 
ve bu hastaların çoğunda fonksiyonel veya bilişsel çeşitli problemler bulunabilmektedir. İleri yaş hastaların önemli bir kısmı hareket için destek kullanır, yalnızca ev içi hareketlidirler veya yatağa bağımlı yaşarlar. Bu durum ileri derecede kas atrofileri, diz veya kalça çevresi kontraktürlerle ilişkilidir. Diğer sorun ise ileri yaş hastalarda sık karşılaşılan demans veya kooperasyon yetersizliğidir. Bu iki faktör hemiartroplasti veya TKA sonrası çıkık riskini artırmaktadır. TKA ile karşılaştırıldığında hemiartroplastinin en önemli avantajı hastadan çıkartılan femur başı büyüklüğünde bir protez baş kullanılabildiği için çıkık riskinin daha düşük olmasıdır. ${ }^{[21]}$ Karar vermede etkili olan bir diğer faktör ise önceden var olan kalça osteoartritidir. ${ }^{[5,17,18]}$ Radyolojik olarak osteoartrit varlığını değerlendirmek mümkün olduğu gibi kırık öncesi kalça ağrısı açısından da hastaları sorgulamak fikir verebilir. Özet olarak, 80 yaş üstü, fizyolojik ileri yaş, yaşam beklentisi kısa (<5 yıl), ek hastalıkları fazla, hareket kabiliyeti kısıtlı ve bilişsel bozukluğu olan hastalarda hemiartroplasti daha güvenli bir seçenektir. ${ }^{[5,6,17-19,21,22]}$ Diğer taraftan, uygun hastalarda TKA'nin hemiartroplastiye göre ağrı ve fonksiyonel sonuçlar açısından daha üstün olduğu gösterilmiştir. ${ }^{[5,6,17-19,21,22]}$ Bu nedenle, bilişsel ve fonksiyonel olarak iyi durumda, görece daha aktif, ev dışı hareketi olan, daha az ek hastalığa sahip ve koksartroz, renal osteodistrofi, enflamatuvar artropati ve Paget gibi kalça hastalıkları olanlarda TKA uygulanmalıdır. ${ }^{[5,6,17,21,22]}$

\section{Parsiyel Unipolar mı, Bipolar mı?}

illk olarak Moore ve Thompson tarafindan uygulanan, monoblok, ilk kuşak parsiyel protezlerin en önemli sorunu görece aktif hastalarda zaman içerisinde gelişen asetabular erozyon veya protrüzyondur. ${ }^{[12]} \mathrm{Bu}$ soruna çözüm olarak, asetabular kıkırdak ile metal protez baş arasındaki sürtünmeyi azaltarak kıkırdak erozyonu ve protrüzyonu önlemeyi hedefleyen, iç içe geçmiş iki baştan oluşan bipolar hemiartroplasti 1974'de geliştirilmiştir ve günümüzde de uygulanmaya devam etmektedir. ${ }^{[6,12]}$ Klinik çalışmalar ise bipolar protezler ile modüler unipolar protezlerin sonuçlarının benzer olduğunu göstermektedir. ${ }^{[23]}$ Günümüzde, hemiartroplastinin ileri yaş, komorbid, düşkün ve fonksiyonel kapasitesi kısıtlı hastalarda uygulandığı düşünüldüğünde, maliyeti daha düşük olan unipolar başlar ile uygulamanın yeterli olacağı görülmektedir. ${ }^{[23]}$ Son olarak, kalça kırıklı hastalarda diğer bir artroplasti alternatifi de 'dual mobil' veya 'tripolar' olarak isimlendirilen, TKA'nin asetabular yüzeyini, hemiartroplastinin de büyük, bipolar baş özelliğini beraberinde taşıyan eklemleşmelerdir. Özellikle çıkık riskinin yüksek olduğu hastalarda TKA ve hemiartroplastiye iyi bir alternatif olarak düşünülmelidir. ${ }^{[24]}$

\section{Femoral Stem Tespit Seçenekleri}

Tarihsel önemi olan, ilk kuşak hemiartroplasti uygulamalarından Austin-Moore protezleri çimentosuz uygulanmıştır. Protez üzerindeki kemik pencereye yerleştirilen, femur başından alınan otogreftin proksimal femur ile kaynamasıyla kararlı tespit hedeflenmiştir. ${ }^{[12]}$ TKA implant teknolojilerindeki gelişmenin de önemli katkısıyla günümüzde kullanılan modern femoral stemler çimentolu veya çimentosuz 'press-fit' olarak uygulanabilmektedir.

Kalça kırıklı hastalarda ileri yaş ve osteoporoz nedeniyle femur anatomisi değişebilmektedir. Trabekül kaybına bağlı olarak medullada genişleme, kortekste incelme ve anterolateral eğrilik en sık görülen anatomik bozukluklardır. Bu nedenle uygulanacak protezin proksimal femur anatomisine uygun olması gerekmektedir. Çimentolu stemlerin çapı daha az olduğundan bu tür hastalarda uygun dizilim ve tespit kolaylığı sağlamaktadır. Enfeksiyon için riskli hastalarda çimento içerisine antibiyotik ekleyebiliyor olmak da diğer avantajıdır. Biyolojik tespite izin veren çimentosuz, gözenek yüzeyli stemler son yıllarda kalça kırıklı hastalarda eskiye oranla daha sık kullanılmaktadır. 'Press-fit' stem uygulamasında ameliyat daha kısa sürmekte ve çimentonun kemik medullasına uygulanmasına bağlı komplikasyonlar da görülmemektedir ancak femurun anatomisi her zaman çimentosuz stemler için uygun olmayabileceğinden hasta seçiminde dikkatli davranılmalıdır. ${ }^{[12,25]}$ Femoral kanal hazırlığı ve temizliğinin uygun yapıldığı, distal tıkaç kullanılan, çimentonun vakumlu ortamda hazırlanıp çimento tabancası ile uygulandığı modern teknikler ile uzun sağkalımlı çimentolu femoral tespit elde etmek mümkündür. ${ }^{[25]}$ Çimentosuz hemiartroplasti hastalarında yukarıdaki nedenlerden dolayı revizyon oranları pek çok çalışmada daha yüksek bulunmuştur. ${ }^{[25,26]} \mathrm{Her}$ ne kadar görece genç, daha aktif ve kemik kalitesi iyi hastalarda çimentosuz femoral stem uygulamak yanlış olmasa da ameliyat süresini kısaltması dışında belirgin avantajı olmadığı göz önünde bulundurulmalı ve periprostetik kırıklar açısından dikkatli olunmalıdır (Şekil 4).

\section{Hemiartroplasti ve Total Kalça Artroplastisinde Cerrahi Yaklaşımlar}

İmplant tasarımı ve uygulama ekipmanlarındaki gelişmeler, ameliyat sürecindeki dönemde hastaların tıbben olabilecek en iyi durumda tutulmasına yönelik değerlendirmeler ve uygun anestezi teknikleri sayesinde kalça kırı̆gı sonrası parsiyel veya TKA ameliyatları hızlı ve güvenli bir şekilde, farklı cerrahi yaklaşımlar yoluyla uygulanabilmektedir. Kalça protezi için uygulanan cerrahi yaklaşımlar, eklem 

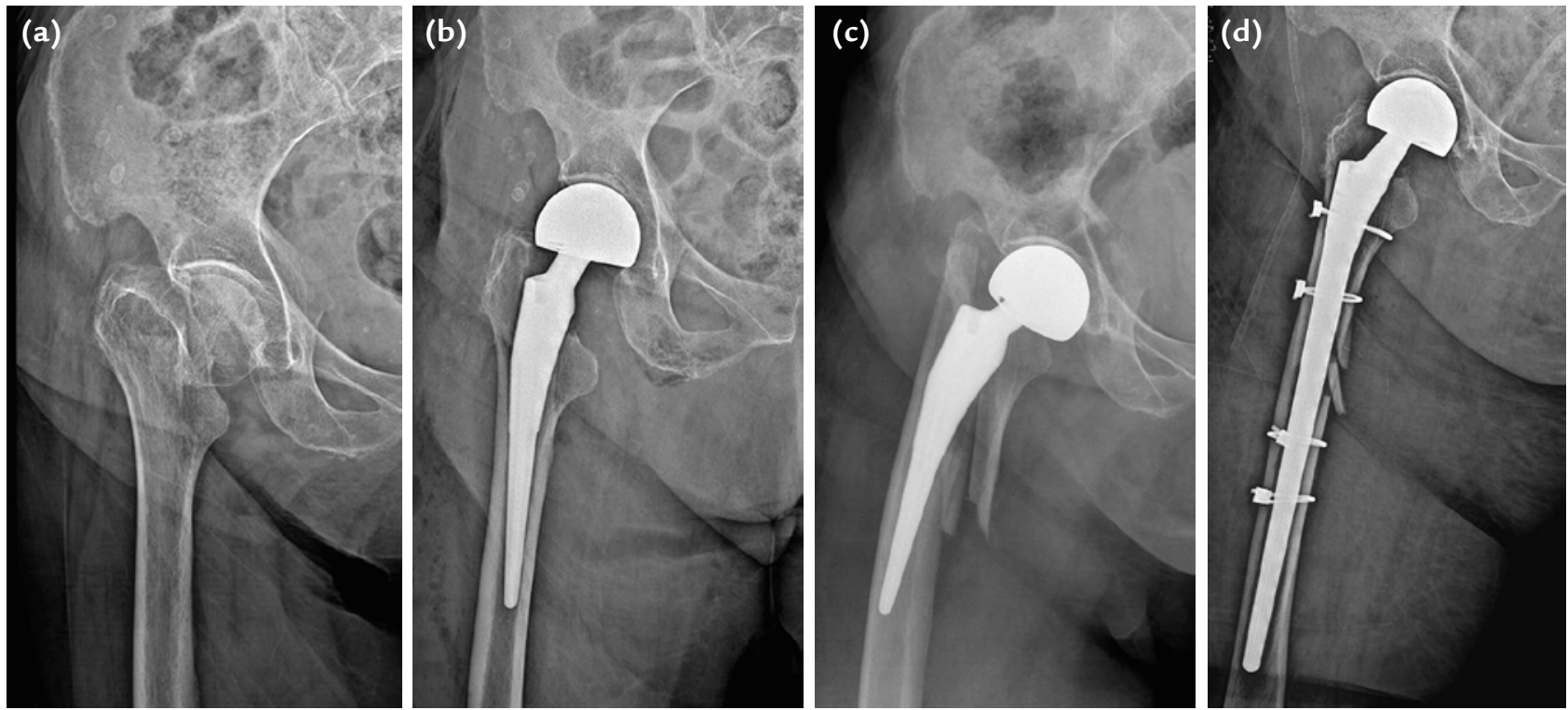

Şekil 4. a-d. Femur boyun kırığı olan 80 yaş kadın hasta (a). Çimentosuz, 'press-fit' hemiartroplasti uygulamasında erken ameliyat sonrası grafisi (b). Ameliyat sonrası tam yük verme ile ortaya çıkan periprostetik kırık (c). Femoral komponent revizyonu ile birlikte periprostetik kırığın tespiti (d).

kapsülünün posterior veya anteriordan açılmasına göre posterior ve anterior yaklaşımlar olarak iki ana başlıkta değerlendirilebilir. Parsiyel veya TKA uygulamasındaki hedef, ameliyatın mümkün olan en kısa sürede, en az cerrahi travma ve kan kaybı ile, ameliyat içi komplikasyonlardan kaçınarak implantların en uygun şekilde yerleştirilmesi olduğuna göre hangi yaklaşımın kullanılacağını cerrahın tecrübesi ve tercihleri belirlemektedir.

Günümüzde TKA uygulamalarında da en sık kullanılan cerrahi yaklaşım posterior (Kocher-Gibson) yaklaşımdır. Bu yol, proksimal femur ve asetabuluma kolay ulaşım ve iyi bir görüntü sağlar. Pek çok seride gösterilen, görece yükssek çıkık riski ise en önemli dezavantajıdır. ${ }^{[27]}$ Bazı yazarlar ise kısa dış rotator adaleler ve kapsülün uygun tamiri sayesinde çıkık riskinin posterior yaklaşım için bir fark oluşturmadığını göstermiştir. ${ }^{[28,29]}$ Kalça kırıklı hastaların önemli bir bölümünün yaşlı, bilişsel sorunları olan, hareket kabiliyetleri kısıtlı, kalça veya diz çevresi kontraktürlere bağlı olarak kalçalarını fleksiyon ve adduksiyon postüründe tuttukları düşünüldügünde, bu hastalar için posterior yönde çıkık riskini azaltacak yaklaşımları tercih etmek daha uygun olacaktır.

TKA'de lateral yaklaşımların posterior yaklaşımlara göre günümüzde daha az kullanılıyor olmasının temel sebebi abduktor tendonların kısmen de olsa kaldırılıyor olmasından kaynaklı ameliyat sonrası topallamadır. ${ }^{[29]}$ Bununla birlikte, posterior kapsülün sağlam bırakılıyor olması nedeniyle kalçanın fleksiyon pozisyonunda posterior yönde çıkık riskinin daha az olması, ileri yaş ve hareket kabiliyeti kısıtlı, destekle hareket edebilen kalça kırıklı hasta grubunda abduktor topallamanın çıkık riski ile karşılaştırıldığında daha az önemli olması bazı yazarlar için halen lateral yaklaşımlar açısından tercih sebebidir. ${ }^{[28]}$ Direkt lateral (Hardinge) ve anterolateral (Watson-Jones) en sık kullanılan lateral yaklaşımlardır. Koksartroz nedeniyle TKA uygulamalarında, Smith-Petersen insizyonu olarak da bilinen direkt anterior yaklaşım, her ne kadar yeni bir cerrahi yaklaşım olmasa da son yıllarda bütün dünyada ün kazanmıştır. Gerçek sinirler arası planlar kullanılarak, hiç bir kas ve tendon kesilmeden yapılabiliyor olması, posterior anatomik yapılara dokunulmuyor olması nedeniyle düşük çıkık riski ve erken fonksiyonel iyi sonuçlar bunun en önemli nedenlerindendir. ${ }^{[30]}$ Hastanın ameliyat masasında sırtüstü pozisyonda hazırlanıyor olması anestezi uygulamaları ve bacak uzunluk eşitleme açısından da avantajlar sağlamaktadır (Şekil 5). Kalça kırıkları sonrası da parsiyel ve TKA için direkt anterior yaklaşım başarılı bir şekilde uygulanabilmektedir. ${ }^{[30]}$ Öğrenme eğrisinin başındaki cerrahlar için bu yaklaşım, özellikle ameliyat içi femoral kırıklar gibi çeşitli komplikasyon risklerini beraberinde getirdiğinden dikkatli olunmalıdır. 

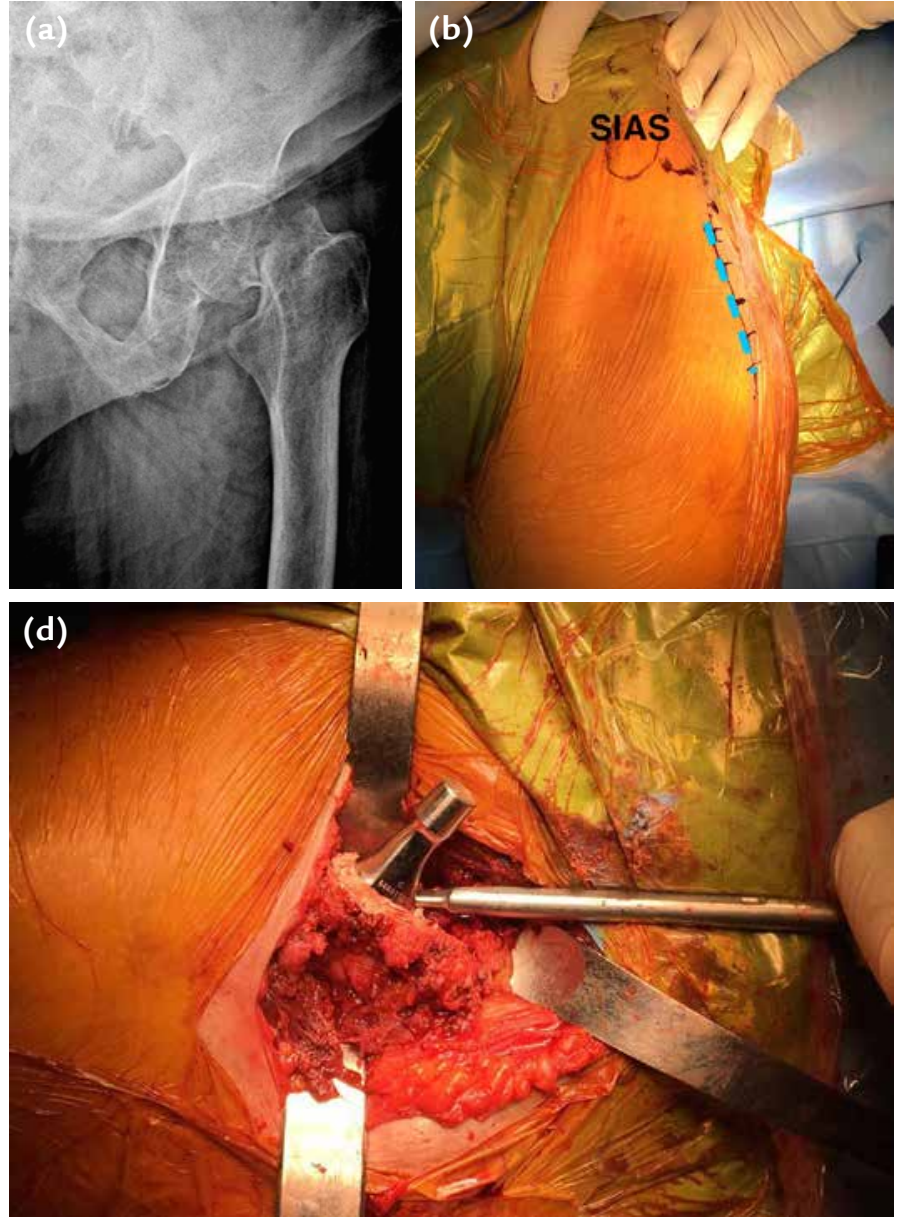
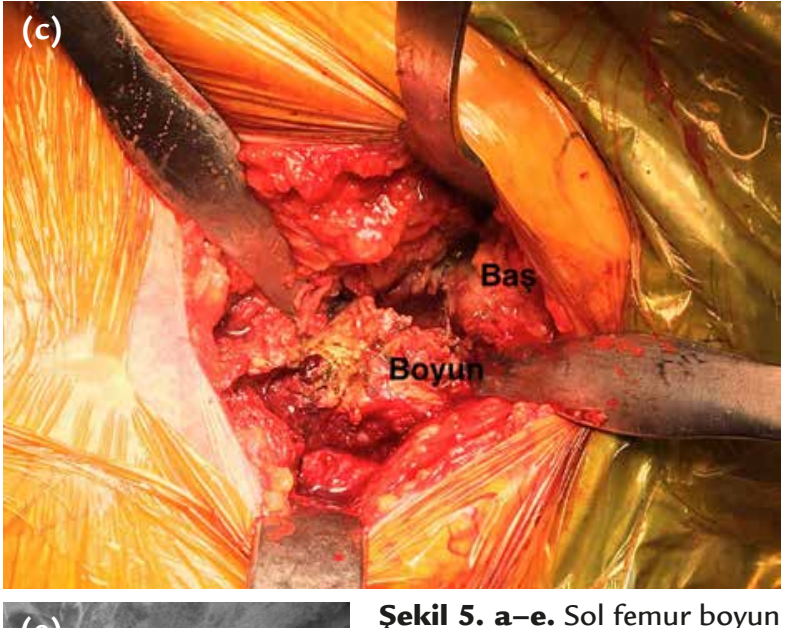
kırığı olan 85 yaş kadın hasta (a). Supin pozisyonda direkt anterior yaklaşım ile hemiartroplasi için hazırlanan hastanın önden görünümü. Mavi çizgi insizyonu göstermektedir (b). Femur başı, boynu ve kırık hattının anteriordan görünümü (c). Protezin çimentolu olarak yerleştirilmesi (d). Ameliyat sonrası grafisi (e).

\section{KAPSÜL DIŞI KALÇA KIRIKLARI}

\section{Intertrokanterik Kırıklarda Artroplasti}

İntertrokanterik kırıkların güncel tedavisi, kırığın açık veya kapalı redüksiyonu sonrası internal tespittir. Günümüzde bu amaçla başta proksimal femur çivileri, kayıcı kalça çivileri ve kilitli plaklar olmak üzere çeşitli implantlar başarılı bir şekilde kullanılmaktadır. ${ }^{[6,12]}$ ileri derecede parçalı ve osteoporotik hastalarda ise parsiyel veya TKA uygulanabilmektedir (Şekil 6). Kırık öncesi koksartrozu veya enflamatuvar artropatisi olan hastalar, eşlik eden aynı taraf femur boyun kırığı olan hastalarda da artroplasti uygun seçenektir. Femur boyun kırı̆gı olan hastalardaki uygulamalardan farklı olarak, özellikle posteromedial parçalanması olan hastalarda, femoral stem uzunluğu belirlenirken kanal çapının 2-3 katı kadar kırık hattının distaline ulaşması hedeflenmelidir. ${ }^{[12]}$ Femur boyun veya kalkar defekti bulunan hastalarda da kalkar destekli veya yakalıklı femoral stemler tercih edilmelidir. Parçalı intertrokanterik kırıklarda
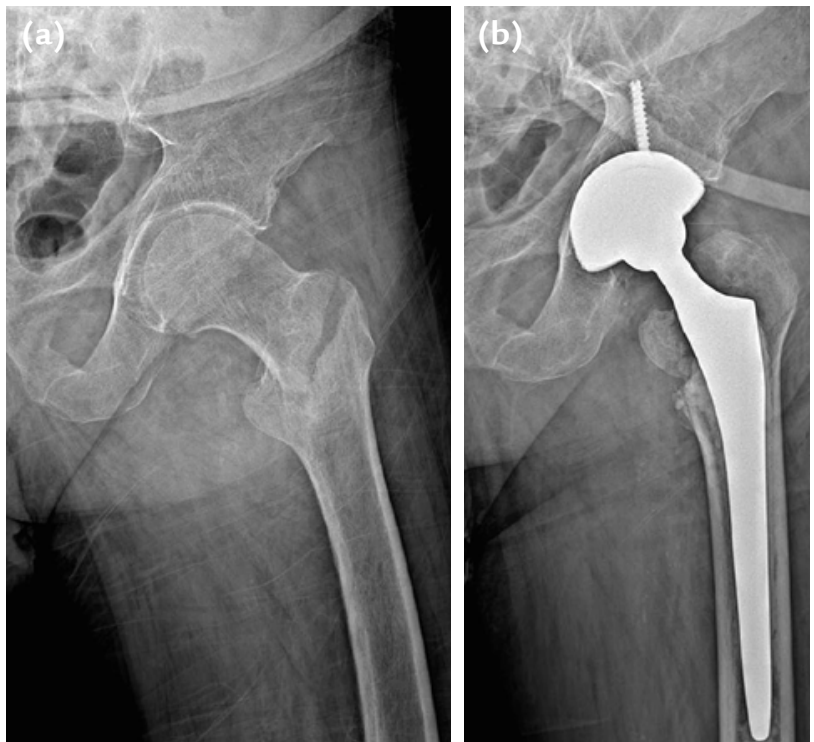

Şekil 6. a, b. Sol intertrokanterik femur kırığı olan 75 yaşında, osteoporoz, demansı olan hastanın grafisi görülmekte (a). Çıkık riskinin yüksek olması nedeni ile dual mobil total kalça artroplasti uygulandı. Ameliyat sonrası grafisi (b). 
anatomik belirteçler bozulmuş olabileceğinden bacak uzunluğunu ve 'offset'i sağlamaya özen gösterilmelidir. Çıkık riskini azaltmak abduktor sistem devamlılığını sağlamak amacıyla büyük trokanterin femoral stem veya kırı̆ı̆ın distaline tespit edilmesi önemlidir. Intertrokanterik kırıklarda da parsiyel veya total protez tercihi yaparken femur boyun kırıkları için yukarıda belirtilen prensipler geçerli olmaktadır. Sonuç olarak intertrokanterik kırıkların tedavisinde ilk seçenek olarak osteosentez düşünülmeli, seçilmiş, parçalı kırığı olan, osteoporotik, kararlı tespit elde edilemeyecek hastalarda artroplasti seçeneği uygulanmalıdır.

Sonuç olarak kalça kırığı gelişmiş olan hastalar ameliyat öncesi dönemden başlanarak çok alanlı bir yaklaşım ile ayrıntılı olarak değerlendirilmeli, kırığın tespiti ya da replasmanı kararı verirken hastanın fizyolojik yaşı, beklentisi, bilinç düzeyi, aktivite seviyesi ve ek hastalıkları dikkate alınmalıdır. Artroplasti ile tedavi edilecek hastalarda hangi cerrahi yaklaşım ve implant sistemlerinin kullanılacağı hastaya özgü olarak karar verilmelidir.

\section{KAYNAKLAR}

1. Bovonratwet $P$, Yang BW, Wang Z, Ricci WM, Lane JM. Operative fixation of hip fractures in nonagenarians: is it safe? J Arthroplasty 2020;35(11):3180-7. Crossref

2. Peeters CM, Visser E, Van de Ree CL, Gosens T, BL Oudsten $D$, Vries JD. Quality of life after hip fracture in the elderly: a systematic literature review. Injury 2016;47(7):1369-82. Crossref

3. Lewiecki EM, Wright NC, Curtis JR, Siris E, Gagel RF, Saag KG, Singer AJ, Steven PM, Adler RA. Hip fracture trends in the United States, 2002 to 2015. Osteoporos Int 2018;29(3):717-22. Crossref

4. Bergström $U$, Jonsson $H$, Gustafson $Y$, Pettersson $U$, Stenlund $\mathrm{H}$, Svensson O. The hip fracture incidence curve is shifting to the right. Acta Orthop 2009;80(5):520-4. Crossref

5. Quinlan ND, Hogarth DA, Chen DQ, Werner BC, Browne JA. Hospital and surgeon reimbursement trends for femoral neck fractures treated with hip hemiarthroplasty and total hip arthroplasty. J Arthroplasty 2020;35(11):3067-75. Crossref

6. Morris VA, Baumgaertner MR, Cooney LM. Medical management of the patient with hip fracture. In: Browner BD, Jupiter JB, Krettek C, Anderson P, editors. Skeletal Trauma: Basic Science, Management and Reconstruction. Philadelphia, PA: Elsevier Saunders; 2015. p.1597-606.

7. Stevens JA, Rudd RA. The impact of decreasing U. S. hip fracture rates on future hip fracture estimates. Osteoporos Int 2013;24(10):2725-8. Crossref

8. Mundi S, Pindiprolu B, Simunovic N, Bhandari M. Similar mortality rates in hip fracture patients over the past 31 years. Acta Orthop 2014;85(1):54-9. Crossref

9. Gu Q, Koenig L, Mather RC, Tongue J. Surgery for hip fracture yields societal benefits that exceed the direct medical costs. Clin Orthop Relat Res 2014;472(11):3536-46. Crossref

10. Miller AG, Bercik MJ, Ong A. Nonagenarian hip fracture: treatment and complications. J Trauma Acute Care Surg 2012;72(5):1411-5. Crossref
11. Ovidiu A, Stefan GT, Dragos P, Bogdan V, Dana AI. Survival of nonagenarian patients with hip fractures: a cohort study. Acta Ortop Bras 2017;25(4):132-6. Crossref

12. Thuan VL, Swiontkowski MF. Intracapsular hip fractures. In: Browner BD, Jupiter JB, Krettek, C, Anderson P, editors. Skeletal Trauma: Basic Science, Management and Reconstruction. Philadelphia, PA: Elsevier Saunders; 2015. p.1607-81.

13. Pipkin G. Treatment of the Grade IV fracture-dislocation of the hip: A review. J Bone Joint Surg Am 1957;39(5):1027-42. Crossref

14. Asghar FA, Karunakar MA. Femoral head fractures: diagnosis management and complications. Orthop Clin North Am 2004;35(4):463-72. Crossref

15. Giannoudis PV, Kontakis G, Christoforakis Z, Akula M, Tosounidis T, Koutras C. Management, complications and clinical results of femoral head fractures. Injury 2009;40(12):1245-51. Crossref

16. Guimaraes RP, Saeki de Souza G, da Silva Reginaldo S, Ono NK, Honda EK, Polesello GC, Riccioli W. Study of the treatment of femoral head fractures. Rev Bras Ortop (English Ed.) 2010;45(4):355-62. Crossref

17. Burgers PTPW, Van Greene AR, Van den Bekerom MPJ, Van Lieshout EMM, Blom B, Aleem IS, Bhandari M, Poolman RW. Total hip arthroplasty versus hemiarthroplasty for displaced femoral neck fractures in the healthy elderly: a meta-analysis and systematic review of randomized trials. Int Orthop 2012;36(8):1549-60. Crossref

18. Ravi B, Pincus D, Khan $H$, Wasserstein D, Jenkinson $R$, Kreder HJ. Comparing complications and costs of total hip arthroplasty and hemiarthroplasty for femoral neck fractures: a propensity score-matched, population-based study. J Bone Joint Surg Am 2019;101(7):572-9. Crossref

19. Wang Z, Bhattacharyya T. Outcomes of hemiarthroplasty and total hip arthroplasty for femoral neck fracture: a Medicare cohort study. J Orthop Trauma 2017;31(5):260-3. Crossref

20. Fixation using Alternative Implants for the Treatment of Hip fractures (FAITH) Investigators. Fracture fixation in the operative management of hip fractures (FAITH): an international, multicentre, randomised controlled trial. Lancet 2017;389(10078):1519-27. Crossref

21. Haynes MS, Ondeck NT, Ottesen TD, Malpani R, Rubin LE, Grauer JN. Perioperative outcomes of hemiarthroplasty versus total hip arthroplasty for geriatric hip fracture: The importance of studying matched populations. J Arthroplasty 2020;35(11):3188-94. Crossref

22. Zi-Sheng A, You-Shui G, Zhi-Zhen J, Ting Y, Chang-Qing Z. Hemiarthroplasty vs primary total hip arthroplasty for displaced fractures of the femoral neck in the elderly: a metaanalysis. J Arthroplasty 2012;27(4):583-90. Crossref

23. Imam MA, Shehata M, Abdallah AR, Ahmed $H$, Kader $N$, Ernstbrunner L, Narvani AA, Kambouroglou G, Mcnamara I, Sallam AA. Unipolar versus bipolar hemiarthroplasty for displaced femoral neck fractures: A pooled analysis of 30,250 participants data. Injury 2019;50(10):1694-1708. Crossref

24. Albanese KM, Deshmane P, Patil N, Larsen DA, Ordway NR. Dual-Mobility Articulations in Femoral Neck Fractures: A Systematic Review of the Literature and Meta-analysis of the Outcomes. J Am Acad Orthop Surg 2020. [Published ahead of print] Crossref

25. Kristensen TB, Dybvik E, Kristoffersen M, Dale H, Engesæter LB, Furnes O, Gjertsen JE. Cemented or Uncemented Hemiarthroplasty for Femoral Neck Fracture? Data from the Norwegian Hip Fracture Register. Clin Orthop Relat Res 2020;478(1):90-100. Crossref 
26. Blythe R, O'Gorman PM, Crawford RW, Feenan R, Hatton A, Whitehouse SL, Graves N. Fixation Method for Hip Arthroplasty Stem Following Hip Fracture: A Population-Level Cost-Effectiveness Analysis. J Arthroplasty 2020;35(6):161421. Crossref

27. Svenøy S, Westberg M, Figved W, Valland H, Brun OC, Wangen H, Madsen JE, Frihagen F. Posterior versus lateral approach for hemiarthroplasty after femoral neck fracture: Early complications in a prospective cohort of 583 patients. Injury 2017;48(7):1565-9. Crossref

28. Parker MJ. Lateral versus posterior approach for insertion of hemiarthroplasties for hip fractures: A randomised trial of 216 patients. Injury 2015;46(6):1023-7. Crossref
29. Matharu GS, Judge A, Deere $K$, Blom AW, Reed MR, Whitehouse MR. The Effect of Surgical Approach on Outcomes Following Total Hip Arthroplasty Performed for Displaced Intracapsular Hip Fractures: An Analysis from the National Joint Registry for England, Wales, Northern Ireland and the Isle of Man. J Bone Joint Surg Am 2020;102(1):21-8. Crossref

30. Langlois J, Delambre J, Klouche S, Faivre B, Hardy P. Direct anterior Hueter approach is a safe and effective approach to perform a bipolar hemiarthroplasty for femoral neck fracture: outcome in 82 patients. Acta Orthop 2015;86(3):358-62. Crossref 